\title{
Simple and Combined Acidic Extraction of Phosphorus from Sewage Sludge Ash
}

\author{
BOGDAN A. MILITARU1', RODICA PODE ${ }^{1 *}$, FLORICA MANEA ${ }^{1}$, PETRICA A. LINUL ${ }^{1,2}$ \\ 'Politehnica University of Timisoara, Faculty of Industrial Chemistry and Environmental Engineering, 2 Victoriei Sq., 300006, \\ Timisoara, Romania \\ ${ }^{2}$ National Institute for Research and Development in Electrochemistry and Condensed Matter, 144 Dr. Aurel Paunescu Podeanu, \\ 500587, Timisoara, Romania
}

\begin{abstract}
A comparative behavior of inorganic and organic acids as extraction agents for phosphorous extraction from sewage sludge ash provided by a municipal wastewater plant from Timis County, Romania, was studied in this work. The physical-chemical and morphological properties were determined by X-ray diffraction, FTIR spectroscopy and scanning electron microscopy. Batch simple extraction experiments with hydrochloric acid, sulfuric acid and citric acid were conducted on the sewage sludge ash for phosphorous extraction. The operating conditions for acidic extraction with each acid and combination of sulfuric acid and citric acid were optimized in relation to the acid type, concentration and liquid:solid (LS) ratio. The combination of sulfuric acid and citric acid in volumetric ratio of 0.5 was chosen as optimum extraction agentfor phosphorus recovery.
\end{abstract}

Keywords: sewage sludge management, sewage sludge ash, phosphorus recovery, acid extraction, inorganic and organic acid combination

It is well-known that the sewage sludge is the main waste produced by the municipal wastewater plants. During the wastewater treatment process, the pollutants from the aqueous phase are transferred into the sludge that is characterized by high organic loading, pathogenic germs and metals [1]. Besides the organic loading, the sludge contains the nutritive elements based on phosphorous, nitrogen and potassium that recommended it as an organic fertilizer [2]. Processing and capitalization of sludge through economical and environmentally friendly processes are of great importance to the local authorities and the industry. Within the European Union, the directives related to the landfilling of the sludge were replaced by the directives that support methods for sludge stabilization and recycling [3-6].

Recovery and capitalization of nutrients from sludge, especially phosphorus, is a main approach of the sewage sludge management [7-9]. Since phosphorus is an essential element for all living organisms, it plays an important role for agriculture and industry [10-12]. The recovery of phosphorous presents a great importance knowing that it is a non-regenerative resource and taking into consideration that the inorganic natural phosphorus cycle takes several millions years $[13,14]$.

Recovery and capitalization of phosphorus from sewage sludge ashes is a research direction often reported in the literature [13-17], considering that the incineration leads the sludge volume reduction and the phosphorous concentration increase [18]. In this context, wetextraction using inorganic [19] or organic acids [17], chelating bases and agents [19-21], electrodialysis [22], thermochemical method [23, 24], conditioning and dewatering processes [25] have been studied.

The main aim of this study was to assess and to optimize the phosphorus extraction performance from the sewage sludge ash obtained from the municipal sewage sludge, using two inorganic acids and an organic acid as extracting agent, in relation with the good efficiency and low impact on environment. The effect of the type and the concentration of the extraction acids and also the effect of the liquid:solid (LS) ratio were investigated. The combination of inorganic and organic acids as extraction agents was studied and, to the best of our know ledge, this approach has not been reported in the literature.

\section{Experimental part \\ Materials}

The sewage sludge used in the study was collected from the biological treatment step of a municipal wastewater treatment plant from Timis County, Romania. The sewage sludge was characterized initially by 76.95 wt.\% humidity, $44.46 \mathrm{wt} . \%$ mineral substances and $55.54 \mathrm{wt} . \%$ volatile substances. After drying at $105^{\circ} \mathrm{C}$ for $20 \mathrm{~h}$, the sludge was calcined at $850^{\circ} \mathrm{C}$ for $3 \mathrm{~h}$ using a Nabertherm B180 oven. The resulted sewage sludge ash was milled, sieved and further the fraction with a particle diameter between 40 and $125 \mu \mathrm{m}$ was selected in order to assure a good homogeneity and contact surface with acidic extraction agent without to affect the separation stage. Hydrochloric acid $(\mathrm{HCl}, 37 \%)$, sulfuric acid $\left(\mathrm{H}_{2} \mathrm{SO}_{4}\right)$ and nitric acid $\left(\mathrm{HNO}_{3}\right)$ of analytical reagent grade used for the extraction experiments were provided by Merck, Darmstadt, Germany. Citric acid of analytical reagent grade was provided by VWR Chemicals, West Chester, United States of America. The total phosphorous concentration was determined in according with the standardized method [26]. The bi-distilled and ultrapure water was used for the analytical method.

\section{Chemical composition of sewage sludge ash}

The sewage sludge ash was digested with aqua regia to determine the initial total phosphorous in according with standardized EPA 4500-P C [26] method and metal contents by atomic absorption spectroscopy.

\section{Phosphorous extraction from sewage sludge ash}

The batch experiments for phosphorous extraction from sewage sludge ash were carried out using two inorganic acids (hydrochloric acid, sulfuric acid) and an organic acid (citric acid). The experiments were performed for each acid and as combination of two acids. In order to establish the optimum conditions for phosphorus extraction, the

\footnotetext{
* email: rodica.pode@upt.ro; Phone: +40256403070
} 
influence of extraction acid type and concentration and of liquid:solid (LS) ratio on the extraction efficiency were studied.

The samples were stirred magnetically at a constant speed for 15 min as contact time that was set-up based on prior experimental tests. Then, the separation of the liquid was achieved by centrifugation. Phosphorous from supernatant was analyzed through standardized EPA 4500P C method [26]. For each determination, the extraction efficiency was expressed as degree of phosphorous concentration extracted in acidic sample versus initial phosphorous concentration.

The combined extraction experiments were carried out under the same conditions of agitation and extraction time, using combinations of citric acid and sulfuric acid of different concentrations and in different volumetric ratios, keeping constant the LS ratio for the given concentrations of acids. All extraction experiments were performed in duplicate and the arithmetic average of the values obtained from the analysis was considered.

\section{Solid phase characterization and analytical methods}

$X$-ray diffraction patterns were recorded by using a Rigaku Ultima IV X-ray diffractometer ( $40 \mathrm{kV}, 40 \mathrm{~mA})$ with CuKa radiation $(\lambda=0.15406 \mathrm{~nm})$ to identify the crystalline phases using PDF 4+ databases.

In order to determine the phosphorus forms, Fourier transform infrared (FTIR) spectra were performed within the range of wavenumbers from 4000 to $400 \mathrm{~cm}^{-1}$ on a Shimadzu IRPrestige-21 FTIR spectrophotometer with a nominal resolution of $4 \mathrm{~cm}^{-1}$. The sample was prepared by mixing the powdered solid with $\mathrm{KBr}$.

The structural characteristics of the sewage sludge ash were determined by transmission electron microscopy. TEM images were recorded using A Titan G2 80-200 electron microscope (FEl Company, Netherlands) with Digital Micrograph software and elemental distribution maps were obtained using Esprit software.

The metal concentrations were determined through atomic absorption spectrometry using a Perkin Elmer Analyst 800 spectrometer and PinAAcle $900 Z$ spectrometer.

\section{Results and discussions}

\section{Chemical characterization of sewage sludge ash}

The comparative data related to the chemical composition of different sewage sludge ashes are presented in table 1. It can be noticed a sewage sludge ash compositional variability that is expected and explained by the nature and composition of the wastewater, influencing the quality of the sludge and the sewage sludge ash. As common characteristics, it can be seen that $\mathrm{Ca}$, $\mathrm{Fe}, \mathrm{P}$ and $\mathrm{Al}$ are the main elements contained in the sewage sludge ash. For the sewage sludge ash of this study, the phosphorous content was $42991 \mathrm{mg} / \mathrm{kg}$ that means a mass percentage of about $4.3 \% \mathrm{P}$ and $9.86 \% \mathrm{P}_{2} \mathrm{O}_{5}$, respectively, being lower in comparison with the reported data [23].

Table 1

CHEMICAL COMPOSITION OF THE SEWAGE SLUDGE ASH

\begin{tabular}{|c|c|c|}
\hline \multirow{2}{*}{ Parameter } & \multicolumn{2}{|c|}{ Sewage sludge ash composition (mg/kg) } \\
\cline { 2 - 3 } & this study & {$[21]$} \\
\hline $\mathrm{P}$ & $42991 \pm 2149$ & 93700 \\
\hline $\mathrm{Ca}$ & $79825 \pm 3991$ & 114000 \\
\hline $\mathrm{Al}$ & $32775 \pm 1639$ & 67200 \\
\hline $\mathrm{Fe}$ & $48804 \pm 2440$ & 58500 \\
\hline $\mathrm{K}$ & $15152 \pm 758$ & 15000 \\
\hline $\mathrm{Cu}$ & $737 \pm 37$ & 767 \\
\hline $\mathrm{Mn}$ & $1228 \pm 61$ & 1190 \\
\hline $\mathrm{Zn}$ & $1531 \pm 77$ & 2330 \\
\hline $\mathrm{Pb}$ & $246 \pm 12.3$ & 122.6 \\
\hline $\mathrm{Cr}$ & $183 \pm 9.15$ & 159 \\
\hline $\mathrm{Ni}$ & $80.5 \pm 4.03$ & 73.3 \\
\hline $\mathrm{Cd}$ & N.D. & 2.1 \\
\hline $\mathrm{Na}$ & $14992 \pm 750$ & 5300 \\
\hline $\mathrm{Mg}$ & $14274 \pm 714$ & 16400 \\
\hline
\end{tabular}

Structural and morphological characterization of sewage sludge ash

$X$-ray diffraction spectrum of the ash is shown in figure 1. It can be noticed the presence of several crystalline phases: $\alpha-\mathrm{SiO}_{2}$ in the form of quart (after PDF 01-0898936), $\mathrm{Ti}_{0.14} \mathrm{Fe}_{1.86} \mathrm{O}_{3}$ as hematite-Ti (after PDF 04-017-9144) and $\mathrm{Ca}_{2.59} \mathrm{Mg}_{0.41}^{1.86}\left(\mathrm{PO}_{4}\right)_{2}$ ) as whitlockite (after PDF 04-0092106). The presence of whitlockite in the sewage sludge ash composition is in agreement with the literature that frequently reported itfor various composition of the sewage sludge $[20,27]$. The presence of phosphorous as whitlockite phase does not recommend the direct use of the sewage sludge as sewage sludge ash form as fertilizer due to its lower solubility in ammonium citrate in comparison with buchwaldite phase as has been reported by Stemnan et al. [16], but P-rich witlockite is readily dissolvable in acid [28]. Under these circumstances, the feasible approach should be phosphorous extraction and capitalization as fertilizer product.

FTIR spectrum of the sewage sludge ash is given in Fig. 2. The band at $3442 \mathrm{~cm}^{-1}$ was assigned to the stretching vibration of $\mathrm{H}_{2} \mathrm{O}$ molecules [29], the band at $1041 \mathrm{~cm}^{-1}$ is attributed to the vibrations $\mathrm{PO}_{4}^{3-}, \mathrm{PO}_{3}^{3-}, \mathrm{Si}-\mathrm{O}-\mathrm{Si}$ (asymmetric stretching vibration) [30], the bands between $690-800 \mathrm{~cm}$. ${ }^{1}$ are assigned to the $\mathrm{Si}-\mathrm{O}$-Si symmetric stretching vibrations [29] and the bands in the range $400-500 \mathrm{~cm}^{-1}$ are attributed to the $\mu_{\text {Ee-0, }} \mu_{\text {si-o }}$ vibrations $[29,30]$.

TEM images presented in figure 3 were recorded at different magnification to get several structures aspects of the sewage sludge ash. An irregular structure of the sewage sludge ash is observed in figure $3 a$ and the presence of small distinct particles is observed in figure
Fig. 1. X-ray spectrum of the sewage sludge ash

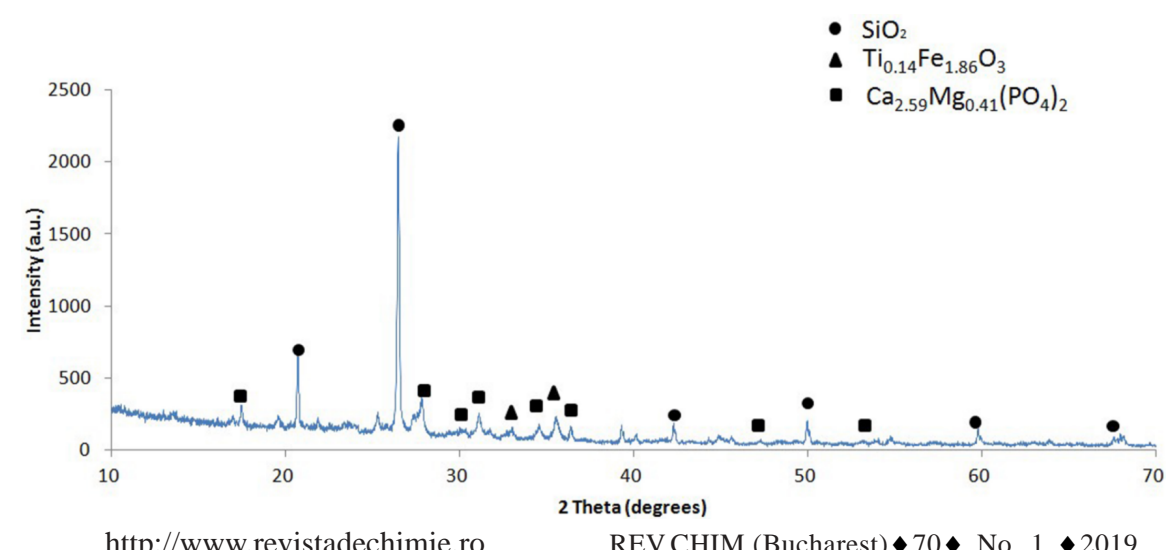

- $\mathrm{SiO}_{2}$

- $\mathrm{Ti}_{0.14} \mathrm{Fe}_{1.86} \mathrm{O}$ 


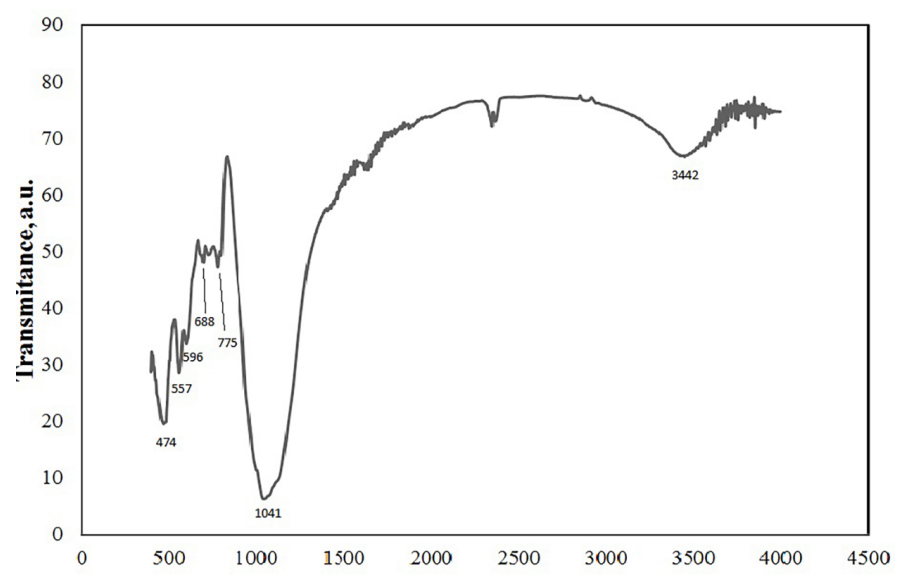

Fig. 2. FTIR vibrational spectrum of the sewage sludge ash
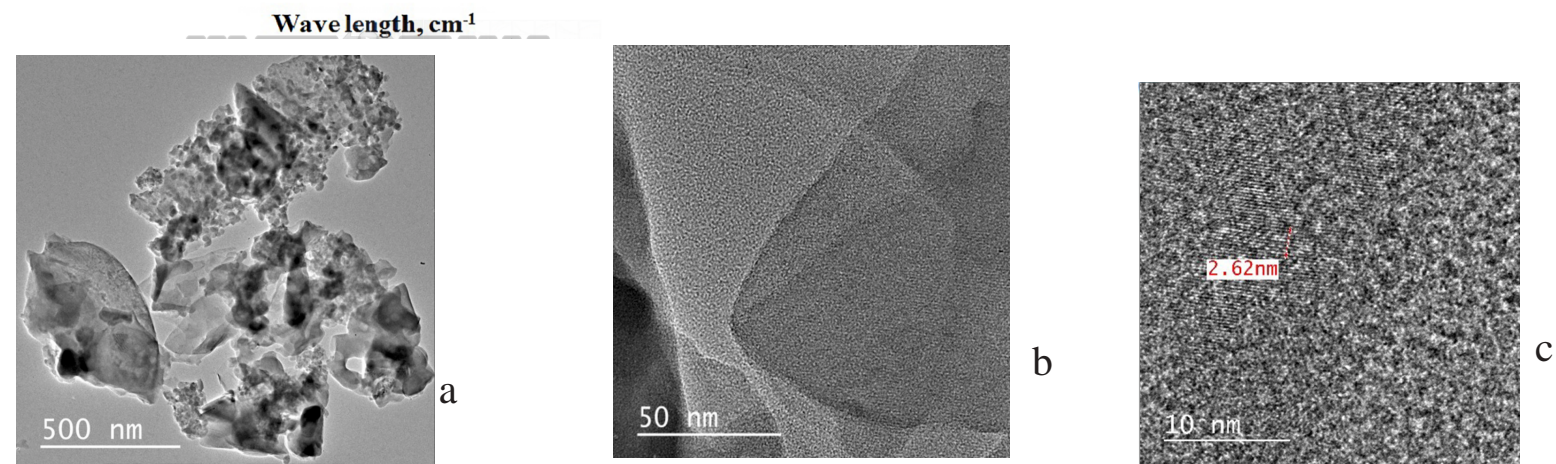

Fig. 3. TEM image - magnification of: (a) $170 \mathrm{kx}$, (b) $155 \mathrm{kx}$ and (c) $730 \mathrm{kx}$

3b. The crystalline particles and non-uniform porosity are evidenced in figure $3 c$.

\section{Extraction studies}

In order to find the simplest way for phosphorous valorization, especially as a fertilizer, this study was conducted to find optimum conditions for its extraction in acidic media as prerequisite and intermediate step of the phosphorous recycling technology. The optimum contact time of 15 min applied in this study was determined based on prior experimental tests and the results are not presented here.

\section{Simple extraction}

The influence of liquid:solid (LS) ratio on the phosphorous extraction efficiency using hydrochloric acid and sulfuric acid is shown in figures $4 a$ and $5 a$. The evolution of the phosphorous concentration in acid media is given in figures $4 b$ and $5 b$ for both acids, whose concentrations ranged from $0.03 \mathrm{M}$ to $0.20 \mathrm{M}$ for $\mathrm{HCl}$ and from $0.03 \mathrm{M}$ to $0.15 \mathrm{M}$ for $\mathrm{H}_{2} \mathrm{SO}_{4}$, respectively.

It can be noticed that increasing $L S$ ratio in the range of 20-100 led to an increase in the phosphorous extraction efficiency and a decrease in the phosphorous concentration in acidic media. Also, LS ratio influence was more significant at lower concentration of the extraction acids. For higher concentrations $(0.20 \mathrm{M}$ for $\mathrm{HCl}$ and $0.15 \mathrm{M}$ for $\mathrm{H}_{2} \mathrm{SO}_{4}$ ), the phosphorous extraction efficiencies were very close independent of LS ratio.

The inorganic acids could cause environmental problems especial as leaching from the extraction treatment. The inorganic acids replacement with the organic acids has been studied as an environmentally acceptable alternative for phosphorous extraction. Taking into account the literature [17], that reported information related to the use of organic acid for the phosphorous extraction from the municipal sludge, the citric acid was used further as the extraction agent. Figure 6a presents

\section{HYDROCHLORIC ACID}

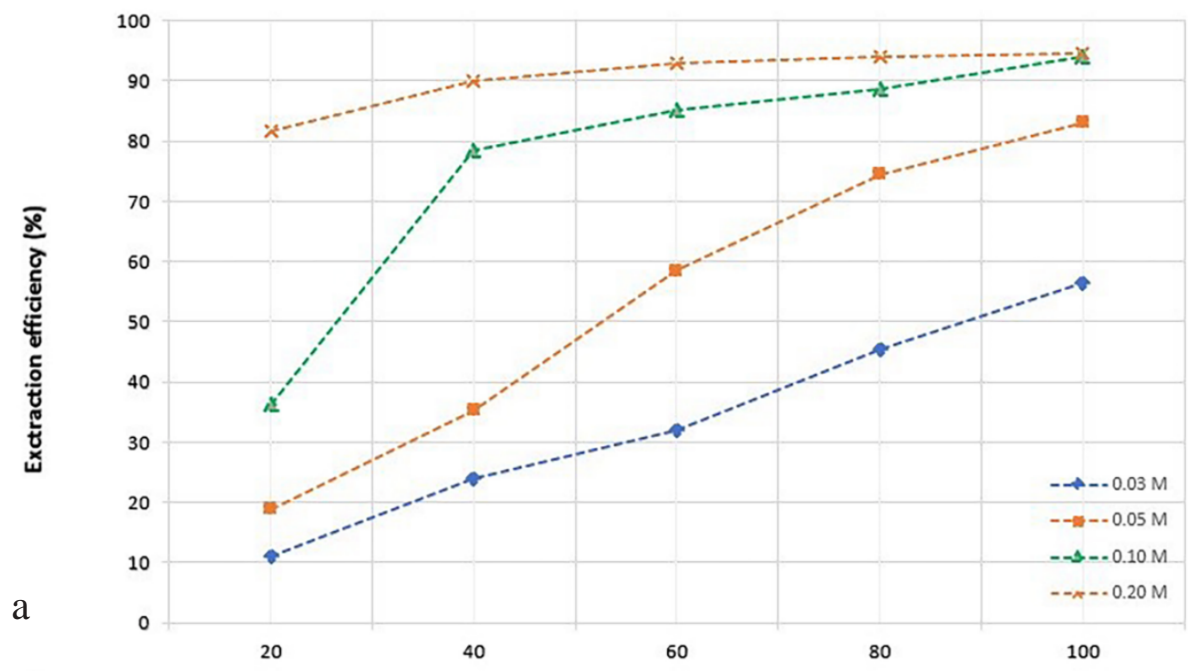

LS ratios
Fig. 4. Phosphorous extraction performance of hydrochloric acid after

15 min contact time at various LS ratios and various acid molar concentrations, expressed as: (a) extraction efficiency 
HYDROCHLORIC ACID

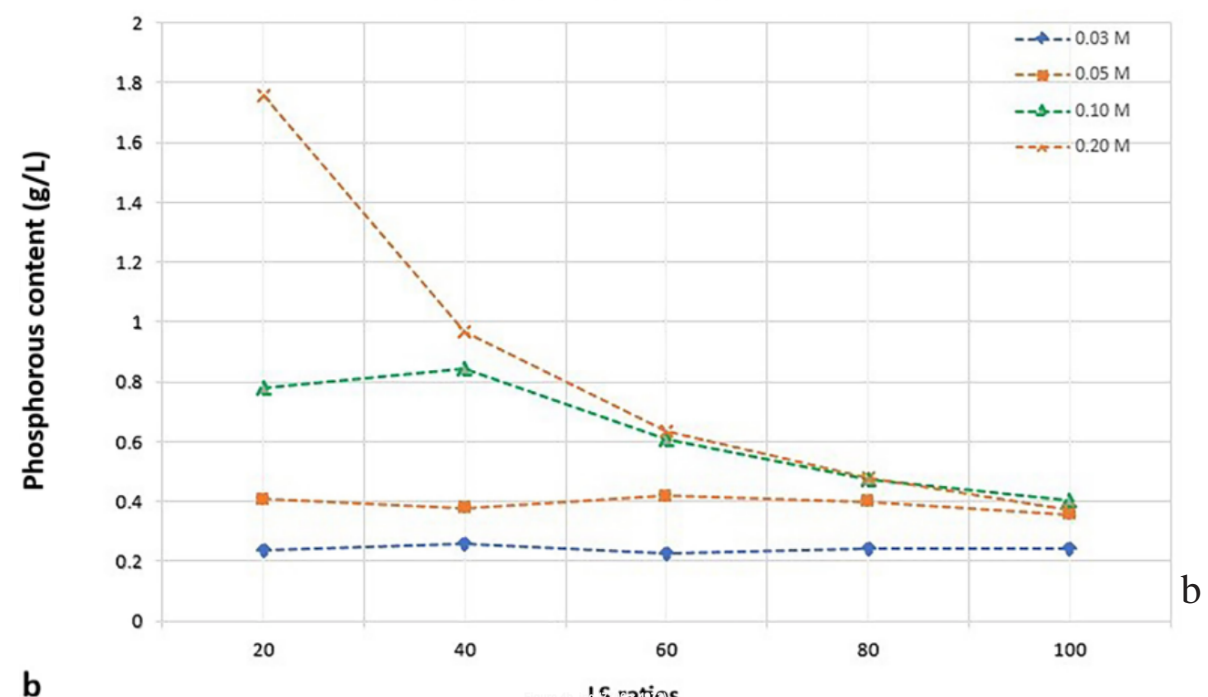

b

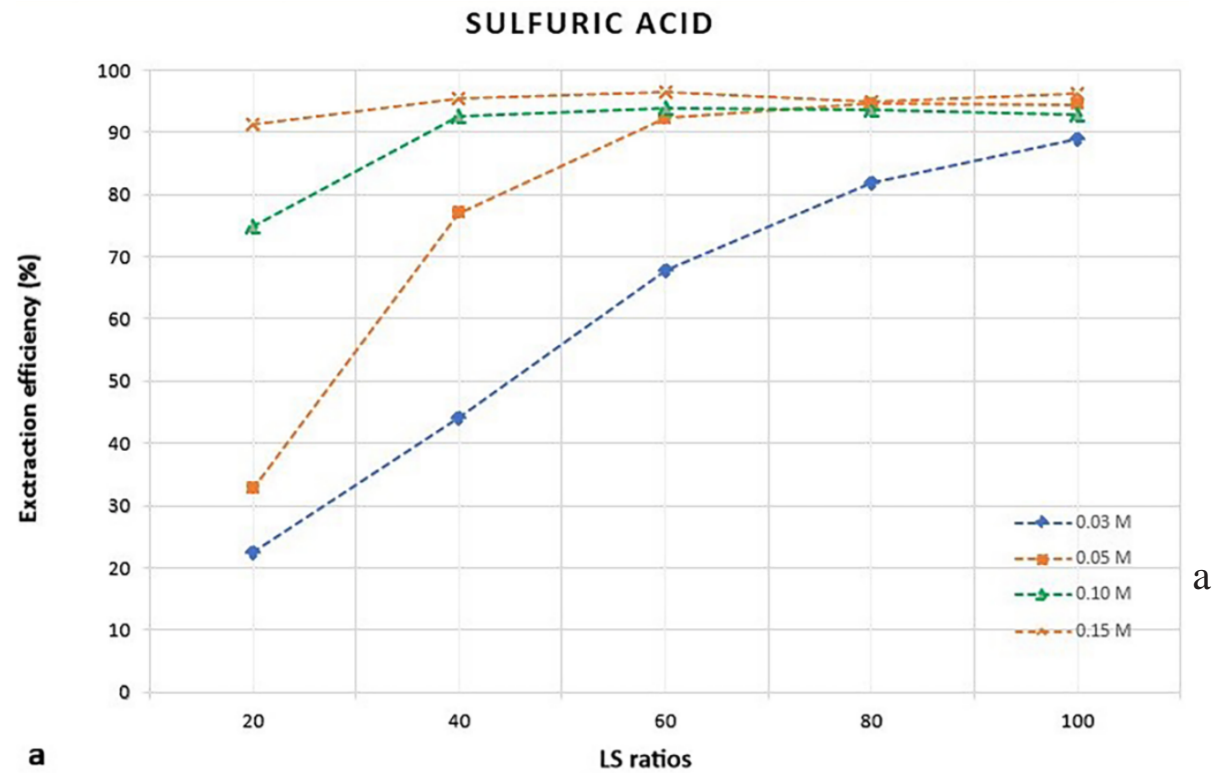

SULFURIC ACID

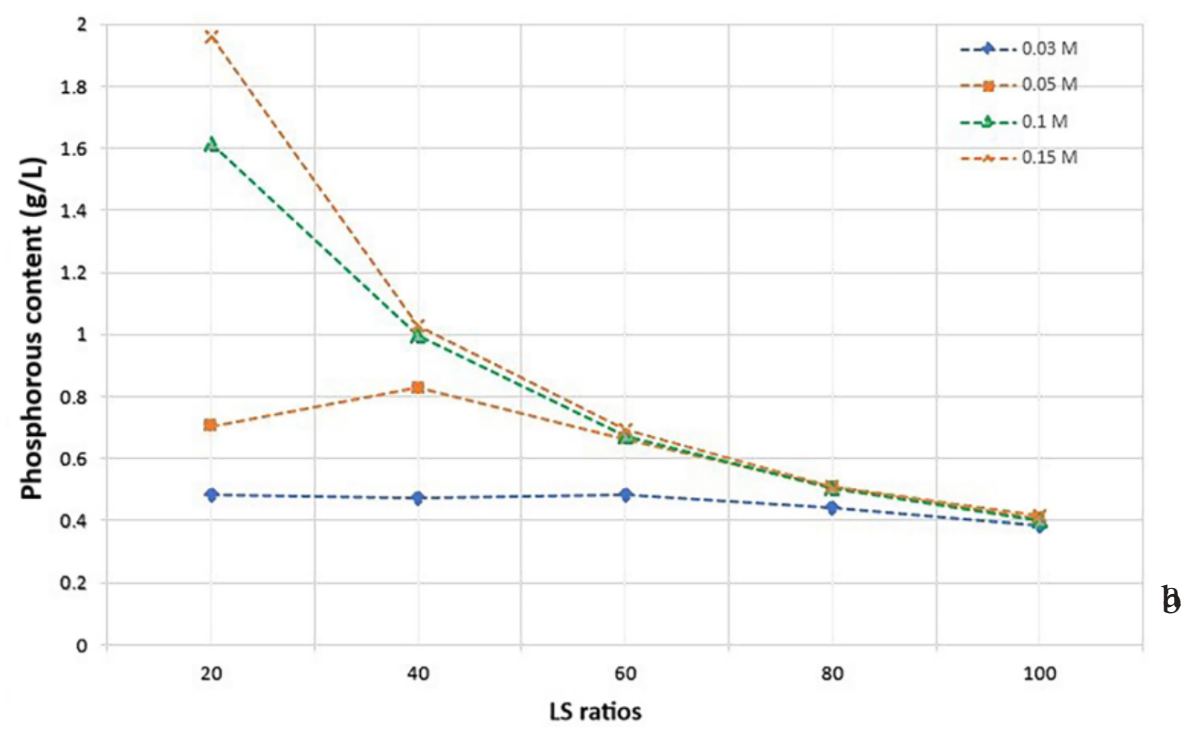

b
Fig. 4. Phosphorous extraction performance of hydrochloric acid after 15 min contact time at various LS ratios and various acid molar concentrations, expressed as: (b) phosphorous content
Fig. 5. Phosphorous extraction performance of sulfuric acid after $15 \mathrm{~min}$ contact time at various LS ratios and various acid molar concentrations, expressed as: (a) extraction efficiency and (b) phosphorous content 
CITRIC ACID

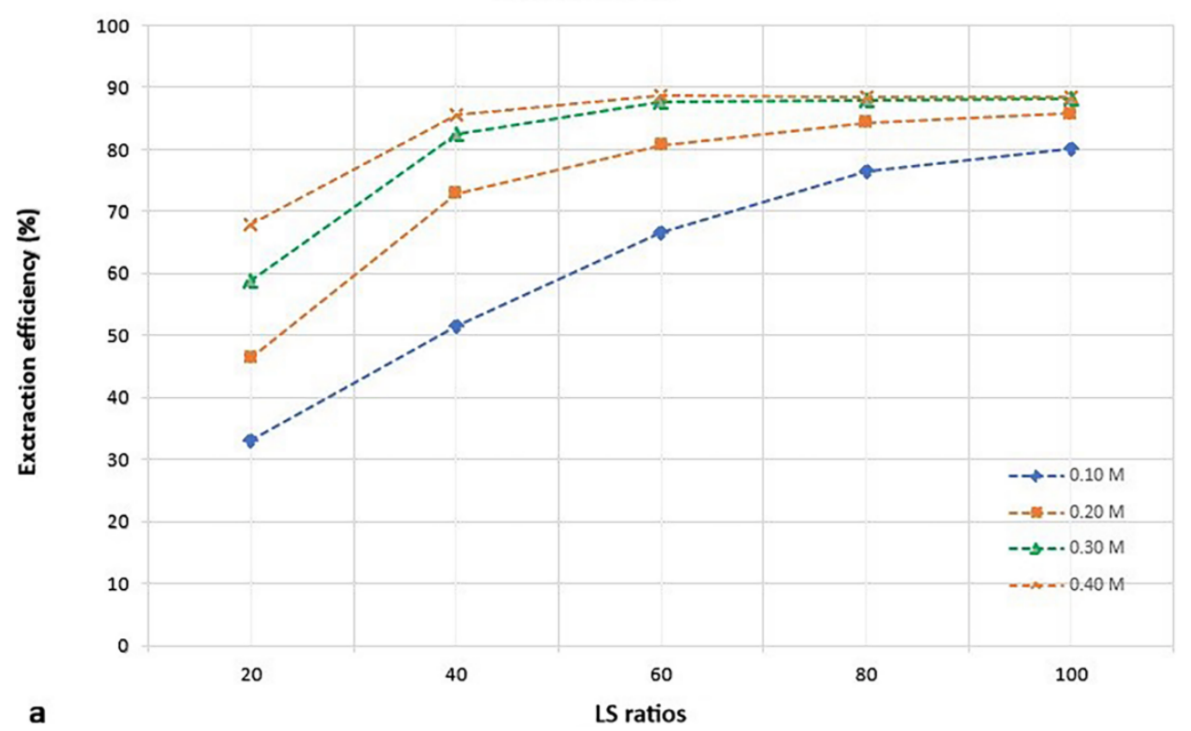

CITRIC ACID

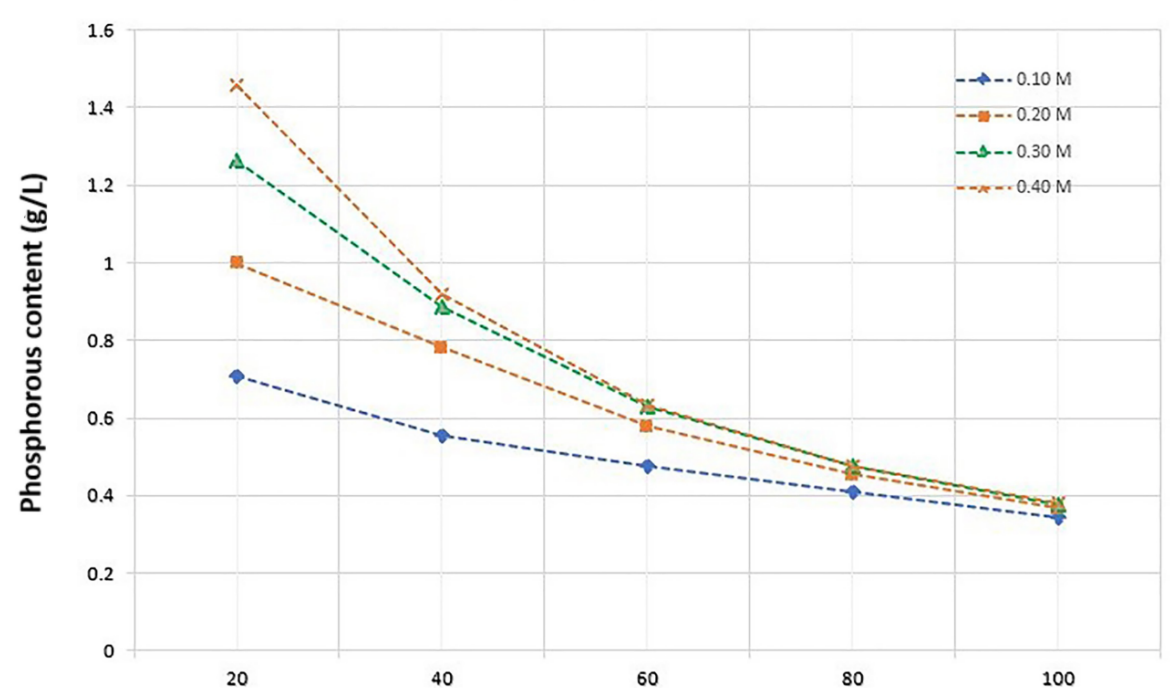

LS ratios

the dependence of extraction efficiency on LS ratio at various values of citric acid concentrations, i.e., $0.10 \mathrm{M}$, $0.20 \mathrm{M}, 0.30 \mathrm{M}$ and $0.40 \mathrm{M}$, which were chosen higher than those of inorganic acids because the organic acids are weaker.

Starting with $0.30 \mathrm{M}$ concentration and LS ratio of $60: 1$ the saturation is reached and the extraction efficiency is kept at about $88 \%$. Also, the phosphorous content into extraction acid solution decreased as LS ratio increased (fig. 6b). Based on the above presented results, it can be concluded that independent of the acid type, a lower LS ratio led to a higher phosphorous content into extraction acid solution. Comparing the results reached for the same concentration of all acids $(0.1 \mathrm{M})$ it can be seen that the sulfuric acid led to the best phosphorous extraction efficiency. This should be explained by the acid strength and $\mathrm{pH}$ value $(2.023$ for citric acid, 1.000 for $\mathrm{HCl}$ and 0.699 for $\mathrm{H}_{2} \mathrm{SO}_{4}$ ). Another explication is given by the fact that $\mathrm{H}_{2} \mathrm{SO}_{4}$ is a diprotic acid in comparison with $\mathrm{HCl}$ that is monoprotic [18].

\section{Combined extraction}

The results of simple extraction studies showed that the inorganic acids were more efficient for the phosphorous extraction in comparison with the organic acid. Taking into account the environmental advantages of citric acid, our further experiments envisaged the effect
Fig. 6. Phosphorous extraction performance of citric acid after 15 min contact time at various LS ratios and various acid molar concentrations, expressed as: (a) extraction efficiency and (b) phosphorous content of the combination of citric acid with sulfuric acid on the phosphorous extraction efficiency and content envisaging extraction improvement.

Practically, it was pursued to improve the extraction process with citric acid at low LS ratio using sulfuric acid addition and taking into account the fact that for the LS ratio of 20:1 the best extraction efficiency of $91.2 \%$ was reached for $0.15 \mathrm{M} \mathrm{H}_{2} \mathrm{SO}_{4}$. The evolution of phosphorous content and extraction efficiency at optimum $0.2 \mathrm{M}$ concentration of citric acid in combination with $0.15 \mathrm{M}$ sulfuric acid at various acid ratios is shown in figure 7. By combination of $0.2 \mathrm{M}$ citric acid characterized by $\mathrm{pH}$ of 1.893 with $0.15 \mathrm{M}$ sulfuric acid at $\mathrm{pH}$ of 0.523 at various values of sulfuric acid:citric acid ratio, the $\mathrm{pH}$ evolution is presented in table 2 .

It is obviously that the combination of citric acid with sulfuric acid enhanced the phosphorous extraction efficiency at $\mathrm{pH}$ value decreasing, which is direct linked to the higher acidic concentration.

Itcan be noticed that the extraction efficiency increased as sulfuric acid:citric acid ratio increased, starting from $46.5 \%$ for single citric acid to $81.4 \%$ for combining sulfuric acid and citric acid in volumetric ratio of 0.5 , which is very close to $91.2 \%$ achieved at $0.15 \mathrm{M}$ sulfuric acid. It can be concluded that the combination of citric acid with sulfuric acid led to enhance the phosphorous extraction efficiency and phosphorous content into extraction acidic solution 
Citric Acid 0.2 M + Sulfuric Acid 0.15 M

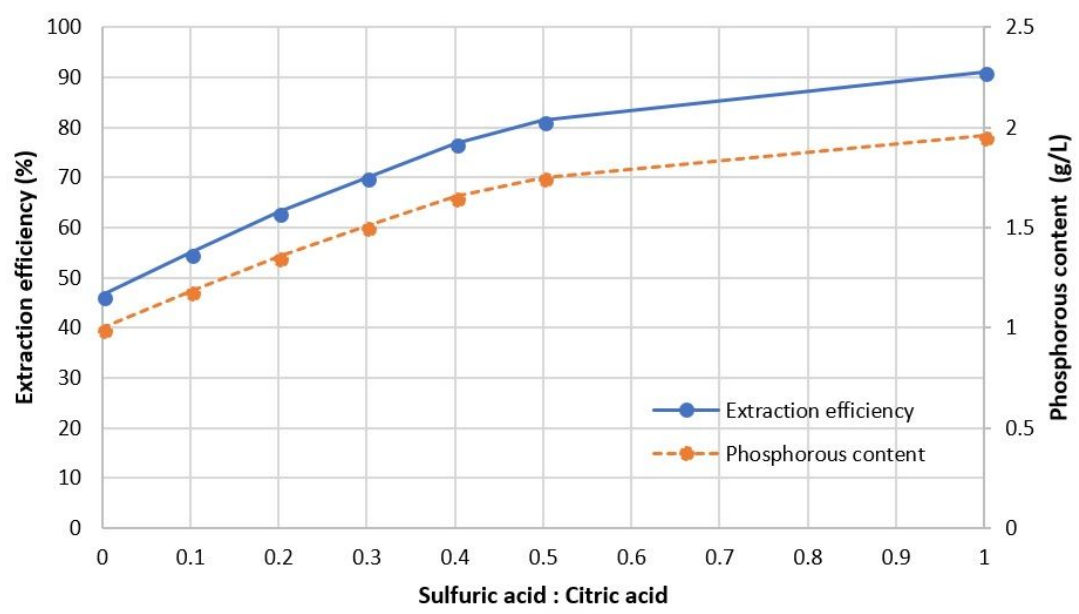

Table 2

PH EVOLUTION OF ACID COMBINATION AT VARIOUS SULFURIC ACID: CITRIC ACID RATIOS

\begin{tabular}{|l|c|c|c|c|c|c|c|}
\hline Sulfuric acid:citric acid ratio & 0 & 0.1 & 0.2 & 0.3 & 0.4 & 0.5 & 1 \\
\hline $\mathrm{pH}$ & 1.893 & 1.675 & 1.444 & 1.314 & 1.224 & 1.137 & 0.523 \\
\hline
\end{tabular}

Table 3

METAL CONCENTRATION IN EXTRACTION ACIDIC AGENT

\begin{tabular}{|l|c|c|c|c|c|c|c|c|c|c|}
\hline \multirow{2}{*}{ Type and concentration of extraction acid } & \multicolumn{8}{|c|}{ Metals concentration in extraction acid (mg/L) } \\
\cline { 2 - 10 } & $\mathrm{A} 1$ & $\mathrm{Cu}$ & $\mathrm{Mn}$ & $\mathrm{Zn}$ & $\mathrm{Pb}$ & $\mathrm{Cr}$ & $\mathrm{Ni}$ & $\mathrm{Mg}$ & $\mathrm{Ca}$ & $\mathrm{Fe}$ \\
\hline $0.15 \mathrm{M}$ sulfuric acid & 518 & 10.4 & 15.7 & 21 & 0.21 & 0.43 & 0.13 & 494 & 1277 & 48.8 \\
\hline $0.15 \mathrm{M}$ sulfuric acid+0.2 M citric acid & 425 & 8.9 & 21.9 & 22.5 & 0.32 & 1.16 & 0.18 & 482 & 1791 & 153.4 \\
\hline
\end{tabular}

and should minimize the environmental impact potential of the residual solutions.

Another important aspect is represented by the presence of the heavy metals in sewage sludge ash, which could be dissolved together with phosphorous and further its purification become another problem to be addressed [18]. Table 3 shows the comparative results of heavy metals extraction in $0.15 \mathrm{M}$ sulfuric acid and the combination of sulfuric acid with citric acid at the ratio of 0.5 . It can be noticed that the presence of citric acid enhanced the extraction of $\mathrm{Ca}, \mathrm{Fe}, \mathrm{Mn}, \mathrm{Cr}$ and $\mathrm{Pb}$ even if extraction solution $\mathrm{pH}$ is higher in comparison with the sulfuric acid because the citric acid can act mainly through complexation, which should assure an involving ligand contribution. For $\mathrm{Al}, \mathrm{Mg}$ and $\mathrm{Cu}$, the citric acid did not show the affinity and slightly reduced their extraction efficiency. Similar results were achieved for $\mathrm{Zn}$ and $\mathrm{Mg}$ for both simple and combined acidic dissolution. These results limit the use of citric acid as an extraction agent.

\section{Conclusions}

The sewage sludge ash resulted from calcination of the sewage sludge originated from a municipal wastewater treatment can be used as phosphorous source for its extraction in acidic solutions using hydrochloric acid, sulfuric acid and citric acid. It was found that the sewage sludge ash composition consisted of $\mathrm{Ca}, \mathrm{Fe}, \mathrm{P}$ and $\mathrm{Al}$. The phosphorous concentration was $42991 \mathrm{mg} / \mathrm{kg}$, which means a mass percentage of about $4.3 \% \mathrm{P}$ and $9.86 \% \mathrm{P}_{2} \mathrm{O}_{5}$, respectively, being lower in comparison with the reported data. The presence of phosphorous was also confirmed by FTIR spectrum and transmission electron microscopymapping technique.

The efficiency of phosphorous extraction depended on the acid type, concentration and liquid:solid ratio. The liquid:solid ratio was chosen as optimum of 20:1 to assure the maximum content of phosphorous in acidic solution for a certain acid concentration. Inorganic acid led to more efficient phosphorous extraction in comparison with citric acid and sulfuric acid exhibited better performance, but the environmental aspects limited its simple usage. The simple extraction with citric acid allowed to lower efficiency for phosphorous extraction and higher content of heavy metals extracted in acidic solution. The combination of the sulfuric acid and citric acid in the volumetric ratio of 0.5 led to better results, thus, the phosphorous extraction efficiency was $81.4 \%$, very close to $91.2 \%$ achieved at $0.15 \mathrm{M}$ sulfuric acid. The combined extraction allowed an enhanced extraction of $\mathrm{Ca}$ and $\mathrm{Fe}$ as well as a slight increase in the concentration of $\mathrm{Mn}, \mathrm{Pb}$ and $\mathrm{Cr}$ that should not influence the further steps of phosphorous capitalization.

Acknowledgements: This work was conceived within the framework of the Doctoral School of Politehnica University of Timisoara and Aquatim S.A. Timisoara.

\section{References}

1.TOCIU, C., ZAHARIA, T., DIACU, E., MARIA, C., MARINESCU F., ILIE M., Rev. Chim. (Bucharest), 68, no. 12, 2017, p. 2752.

2. ILIE, L., MIHALACHE, M., MADJAR, M.R., CALIN, C., SCAETEANU, G.V., Rev. Chim. (Bucharest), 69, no. 3, 2018, p. 561.

3. BART£OMIEJ , M., JACEK, N., PIOTR, K., J. Clean Prod., 90, 2015, p. 1.

4. *** THE COUNCIL OF THE EUROPEAN UNION. COUNCIL DIRECTIVE 1999/31/EC, Landfill Directive 1999/31/EC, Official Journal of the European Communities, L182, 1999, p. 19.

5. *** THE COUNCIL AND THE PARLIAMENT OF THE EUROPEAN UNION, Waste Incineration Directive 2000/76/EC, Official J ournal of the European Communities, L332, 2000, p. 91.

6. *** THE COUNCIL AND THE PARLIAMENT OF THE EUROPEAN UNION, Waste Framework Directive 2008/98/EC, Official J ournal of the European Communities, L312, 2008, p. 3. 
7. MAURICIO, C.U., GJERGJ , D., J OSIANE, P., KEIICHI, S., TOYOHISA F., Adv. Pow der Technol., 28, no. 3, 2017, p. 755.

8. RUNDONG, L., WENCHAO, T., YANLONG, L., WEIYUN W., RUOQI,

C., TIANHUA Y., J. Clean Prod., 140, no. 2, 2017, p. 964.

9. SANDER, A, ELS, N., Calphad., 55, no. 1, 2016, p. 26.

10. CHEN, M., GRAEDEL, T.E., J. Clean Prod., 9, 2015, p. 337.

11. HAIMING, H., JIAHUI, L., LI, D., J. Clean Prod., 102, 2015, p. 437

12. BLOCHER, C., NIEWERSCH, C., MELIN, T., Water Res., 46, 2012, p. 2009.

13. CORDELL, D., DRANGERT, J., WHITE, S., Glob. Environ. Change, 19, 2009, p. 292.

14. LEE, C.G., ALVAREZ, P.J .J ., KIM H.G., JEONG, S., LEE, S., LEE, K.B., LEE, S.H., GHOI, J.W., Chemosphere, 193, 2018, p. 1087.

15. GUEDES, P., COUTO, N., OTTOSEN, L.M, KIRKELUND, G.M., MATEUS, E., RIBEIRO, A.B., Waste Manag., 52, 2016, p. 193.

16. STEMANN, J ., PEPLINSKI, B., ADAM, C., Waste Manag., 45, 2015, p. 385.

17.ATIENZA-MARTINEZ, M, GEA, G., ARAUZO, J., KERSTEN, S.R.A., KOOTSTRA, A.M.J., Biomass Bioenerg., 65, 2014, p. 42.

18. LI, J., TSANG, D.C.W., WANG, Q., FANG, L., XUE, Q., POON C.S., Chemosphere, 186, 2017, p. 350.

19. GUEDES, P., COUTO, N., OTTOSEN L.M, KIRKELUNG, G.M., MATEUS, E., RIBEIRO, A.B., Waste Manag., 52, 2016, p. 193.

20. PETZET, S., PEPLINSKI, B., CORNEL, P., Water Res., 46, no. 12, 2012, p. 3769.
21. GHEJU, M., PODE, R., MANEA, F., Hydrometall., 108, nos. 1-2, 2011, p. 115.

22. GUEDES P., COUTO, N., OTTOSEN, L.M., RIBEIRO, A.B., 34, no. 5 , 2014, p. 886.

23. HERZEL, H., KRUGER, O., HERMANN, L., ADAM, C., Sci. Total Environ., 542, 2016, p. 1136.

24. OSHITA, K., IWASHITA, M., TAKAOKA, M., TAKEDA, N., Environ. Eng. Res., 40, 2003, p. 395.

25. MANEA, F., POP, N., VLAICU, I., PODE, V., PODE, R., Rev. Chim. (Bucharest), 58, no. 11, 2007, p. 1149.

26. FRANSON, M.A.H. (managing editor), Standard methods for the examination of water and wastewater, 21st edition, American Public Health Association, Washington, 2005.

27. NOWAK, B., ASCHENBRENNER, P., WINTER, F., Fuel Process. Technol., 201, 2013, p. 105.

28. KLEEMANN, R., CHENOWETH, J., CLIFT, R., MORSE, S., PEARCE, P., SAROJ, D., Waste Manag., 60, 2017, p. 201.

29. MUSIC, S., FILIPOVIC-VINCEKOVIC, N., SEKOVANIC, L., Brazil. J . Chem. Eng., 28, no. 1, 2011, p. 89.

30. BALABAN, T., BANCIU, M., POGANY, I. I., Applications of physical methods in organic chemistry, Scientific and Encyclopedic Publishing, Bucharest, 1983.

Manuscript received: 12.06 .2018 